https://doi.org/10.33871/23594381.2020.18.1.167-171

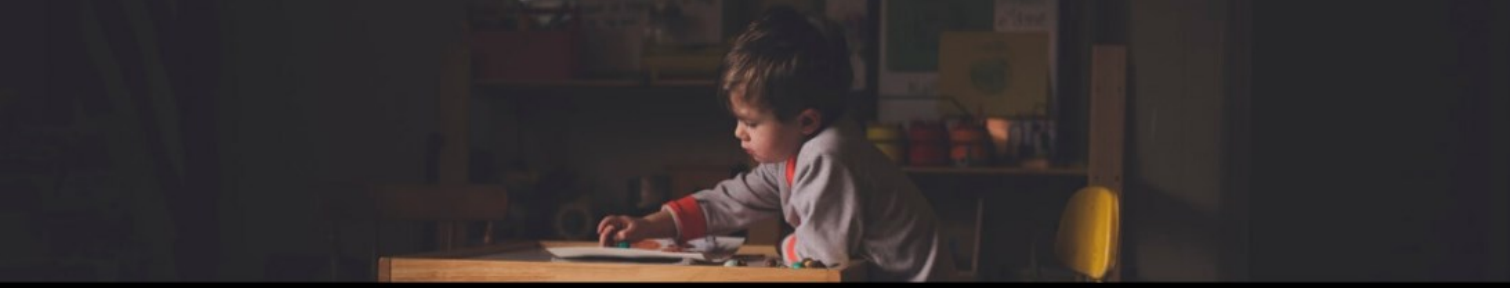

Ensino \& Pesquisa magazine is an interdisciplinary journal of the State University of Paraná, Center for Humanities and Education. Its objective is to publish scientific articles focused on undergraduate and teacher education. (Preprints Policy-AUTHOREA Plataform) ISSN: 2359-4381

\title{
Museus, artes e olhares: as perspectivas de docentes e crianças em espaços inclusivos
}

Bruno Gedra, Mestrando do Programa de Pós-Graduação em Ensino de História ProfHistória, Unespar, Campo Mourão, bruno.gedra@escola.pr.gov.br

Michel Kobelinski, Pós-Doutorado em História, Professor de História da América e dos Programas de Mestrado em História Pública (HP) e Ensino de História (Profhistória), Membro da Federação Internacional de História Pública (IFPH), mkobelinski@gmail.com

Submissão: 2020-01-18. Aprovação: 2020-03-03. Publicação: 2020-04-17

https://doi.org/10.33871/23594381.2020.18.1.167-171

Museu, Educação e Cultura: encontros de crianças e professores com a arte. LEITE, Maria Isabel; OSTETTO, Luciana E. (orgs.). São Paulo: Papirus, 2015, 242p.

O livro Museu, Educação e Cultura: encontros de crianças e professores com a arte, foi organizado por Maria Isabel Leite e Luciana Esmeraldo. A obra traz uma série de textos que buscam problematizar as relações entre museu, educação e cultura, através de uma leitura que apresenta uma rica diversidade cultural presente na escrita de pesquisadores e professores dedicados ao tema.

A obra reúne textos que apresentam os resultados de pesquisas que foram realizadas em museus de grandes centros do país. De forma teórica e analítica é feita uma conceituação de museus e de

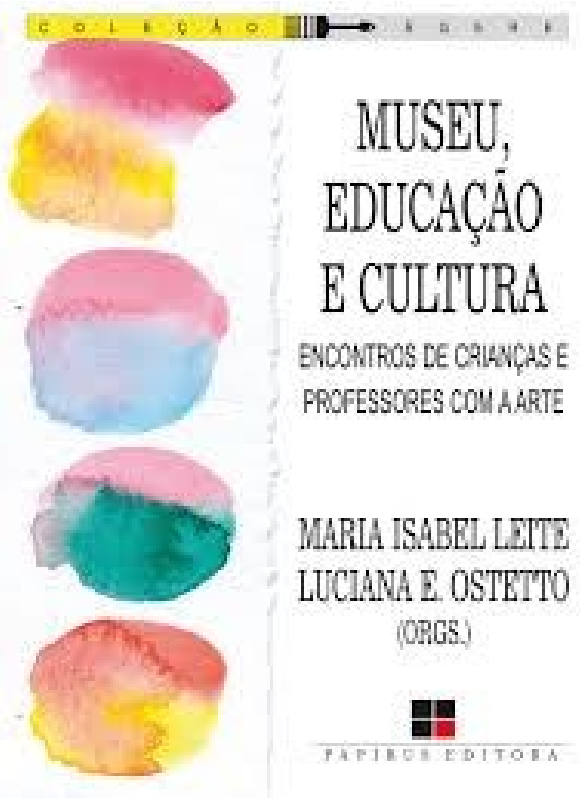


outros espaços culturais como lugares de preservação da memória cultural e de construção do conhecimento.

No primeiro capítulo, no texto Museu de arte: espaços de educação e cultura, Maria Isabel Leite traz um interessante dialogo com alguns autores para apresentar o museu como um campo privilegiado para a experiência estética. Segundo Leite, o museu que se propõe a abrigar a arte deve proporcionar aos visitantes momentos de interação e sensibilização com a obra de arte, ou seja, não basta visitar o museu, o indivíduo precisa ser reconhecido como um sujeito que também é produtor de cultura, assim como um consumidor crítico de cultura que é capaz de "apropriar-se de múltiplas linguagens, tornando-o mais aberto para a relação com o outro, favorecendo a percepção de identidade e alteridade" (p.25).

Leite discute o papel educativo dos museus de arte fazendo uma sistemática problematização sobre a formação de monitores que atuam nos museus apresentando dados que indicam a importância da capacitação desses profissionais para os museus, já que são eles que irão lidar com o público, que muitas vezes é leigo.

No capítulo 2, "Museu do brinquedo como centro cultural infantil", as autoras Telma Anita Piacentini e Monica Fantin, mergulham na memória de uma geração através da coleção de brinquedos e brincadeiras do Museu do Brinquedo, da Universidade Federal de Santa Catarina (UFSC). O museu foi criado em 1999 e, reúne um acervo de brinquedos de diversas origens e culturas. $\mathrm{O}$ museu é itinerante o que permite a exposição do seu acervo em diferentes espaços e lugares, favorecendo a acessibilidade e o seu uso pedagógico. Segundo as autoras, "a presença de um museu com tais características proporciona, às gerações atuais e às futuras, a possibilidade de estudos de identificação do universo pessoal e social da existência humana" (p.73).

Para Piacentini e Fantin, a criação de um museu do brinquedo permite a preparação e formação de um público que seja capaz de compreender o trabalho artístico e cultural, situação que contribui para desfazer a ideia de inacessibilidade dos museus que muitas vezes cria o sentimento de ignorância no visitante.

Gabriela Salles Argolo, no capítulo 3, denominado Olhares e saberes do encontro com a arte, apresenta um olhar sobre o papel dos guardas nos espaços museais, que segundo ela vai muito além da função de guardião do museu e das coleções. Para Argolo, a presença de guardas nos museus gerava nela um sentimento desagradável de controle.

Ensino \& Pesquisa, União da Vitória, v. 18, nº 1, p. 167-171, jan./abr., 2020. 
"Uma presença inibidora de qualquer ato mais entusiasmado por parte do visitante: olhos sempre atentos, ar preocupado, percorrendo os corredores ou imóveis..." (p. 95). No entanto, ao entrevista-los a autora descobre que eles foram tocados pelo diálogo com a arte e, que houve um contato que transcendeu aquela aparência sisuda de guarda patrimonial e permitiu que fossem em busca de conhecimento sobre os artistas e suas obras.

No capítulo 4, Turbilhão de sentimentos e imaginações: as crianças vão ao museu, ou ao castelo..., a autora Adriana Aparecida Ganzer relata a experiência de crianças com idade entre 4 e 6 anos quando visitaram Museu de Arte do Rio Grande do Sul. Ganzer reflete sobre como ações educativas podem aproximar a relação entre instituições escolares e culturais permitindo um processo de aprendizagem que aproxime a arte da educação através da percepção e da sensibilidade. Segundo a pesquisadora a motivação da visita ao museu, o trajeto percorrido, a curiosidade que instiga a imaginação e a fantasia das crianças, assim como os sentidos que são aguçados pelas cores e cheiros estimulam a criatividade e a sensibilidade. Os resultados apresentados nos depoimentos das crianças demonstraram a heterogeneidade de percepção de cada criança quando visitou o Museu de Arte. Como afirma a pesquisadora "a visita ao Museu de arte provoca o gosto pela descoberta das impressões sensoriais, a curiosidade e o prazer" (p.114). No entanto, Ganzer faz uma discussão para saber como isso acontece na prática, como museus e escolas se relacionam a esse respeito, já que para ela o trabalho educativo deve acontecer de forma fruída e sensível propondo um novo olhar para as coisas corriqueiras e privilegiando o diálogo entre o visual e o verbal nos processos de ensino.

No capítulo 5, intitulado $O$ seu olhar melhora o meu: o processo de monitoria em exposições itinerantes a pesquisadora Adriana de Almeida Machado apresenta o resultado de sua experiência como coordenadora da Ação Educativa da mostra "Lasar Segall Exposição digital" e na curadoria da exposição itinerante Brasil século XIX: Imagens da cultura - Exposição digital. Machado relata que a experiência com essas exposições modificou suas perspectivas teóricas "e instigou reflexões sobre a relação sujeito/obra baseada em reproduções" (p.124). A pesquisadora afirma ter se interessado pelo modo como o olhar dela e "dos monitores que integraram as exposições foram mutuamente modificados pelo olhar dos outros, sobretudo do público visitante" (p.124). Refletindo sobre o trabalho realizado na Ação Educativa, Machado conclui que aprendeu mais com o 
público e na formação dos monitores das exposições do que com o estudo de dados teóricos.

Cristina Carvalho no capítulo 6, Espaços de cultura e formação de professores/monitores relata a sua experiência como coordenadora pedagógica e o acompanhamento da monitoria desempenhada por estagiários de graduação em pedagogia e de licenciatura em história, na exposição "Palácio Tiradentes: Lugar de memória do Parlamento brasileiro" realizada na Assembleia Legislativa do Rio de Janeiro. No texto Carvalho dialoga com vários autores para refletir sobre a relação entre escola, museus e centros de cultura, a formação de docentes e cultura e, o conceito de "hibridização cultural”. Ela também traz os pensamentos do cineasta e semiólogo Pier Paolo Pasolini que discute "a linguagem pedagógica das coisas". É feita uma reflexão sobre o currículo e a formação de professores apontando para a necessidade de políticas públicas que tenham como prioridade a formação docente.

A segunda parte do livro reúne textos que apresentam experiências vividas por professores quando visitaram museus. São relatos subjetivos, que demonstra a heterogeneidade dos olhares e da percepção de cada visitante. Por exemplo, Ostetto no texto De luzes e vôos: em busca da beleza para ser humano, faz uma reflexão sobre a importância de se render aos espaços museais, que para ela são lugares de aprendizagem, devaneio e fruição.

No artigo Ampliando meu repertório vivencial, viajando e entrando no museu, Magda Ugioni do Livramento apresenta sua experiência em museus e, com a arte contemporânea. Ela relata suas visitas ao Museu da Universidade de São Paulo (USP) e a Pinacoteca de São Paulo. Para ela visitar esses lugares permitiu compreender a importância dos mesmos para a educação.

Samantha Fernandes da Silva no texto Meu encontro com Picasso...e comigo, faz um relato de sua visita à Exposição Paplo Picasso em São Paulo. Ela recorda sua infância e sua época de escola, que foi de certo modo traumática, pois, segundo ela, a escola foi um lugar que inibiu sua criatividade. Ao longo do texto Silva reflete sobre o processo imaginativo e criativo de Picasso, que além de mexer com suas lembranças e emoções trouxe uma nova perspectiva para a sua prática pedagógica.

No texto O escolar - como Van Goch me fez pensar sobre escola Celia Lucia Baptista Flores discute sobre a importância das experiências estéticas na ação do fazer 
pedagógico partindo de suas impressões da visita que fez a exposição História em Quadros - Pinturas de Mauricio de Souza, no Museu de Belas Artes do Rio de Janeiro.

Rita Márcia Magalhães Furtado relata sua experiência na exposição "Da antropofagia a Brasília”, realizada no Museu de Arte Brasileira, que fica na Fundação Armando Álvares Penteados, em São Paulo, que aconteceu de dezembro de 2002 a março de 2003, em comemoração aos 80 anos da Semana de Arte Moderna. Para ela foi uma experiência ímpar ter contato com as obras dos inúmeros artistas do movimento modernista no Brasil, dando destaque para o Abaporu, de Tarsila do Amaral.

A análise do livro Museu, Educação e Cultura: encontros de crianças e professores com a arte permite o aprofundamento teórico sobre os assuntos referentes à educação, cultura e arte. O livro da voz para os professores que tiveram ricas experiências em museus e com isso puderam repensar suas práticas pedagógicas, por isso, a leitura da obra é extremamente importante para pesquisadores e professores dedicados ao tema.

Ensino \& Pesquisa, União da Vitória, v. 18, nº 1, p. 167-171, jan./abr., 2020. 